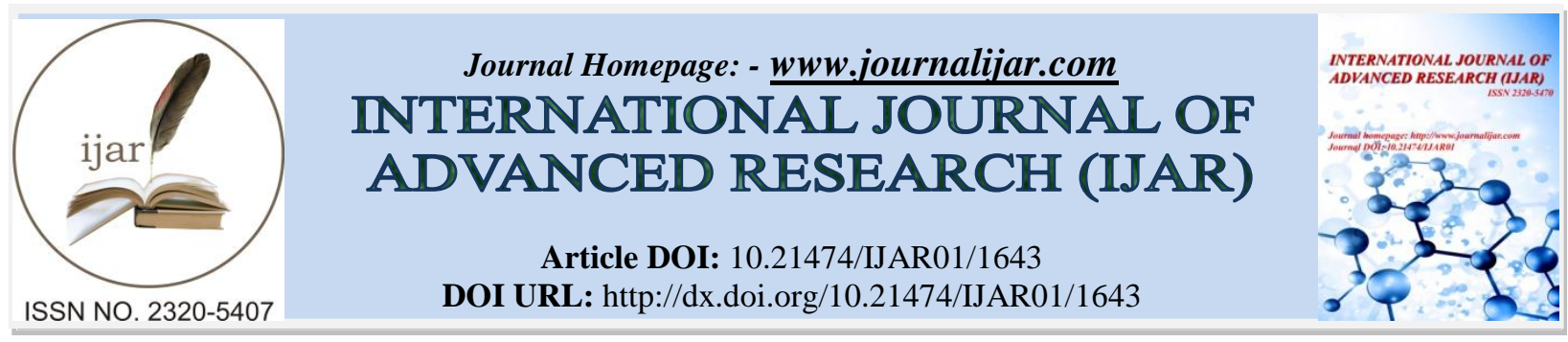

RESEARCH ARTICLE

\title{
THE MORPHOLOGICAL ESTIMATION EFFICIENCY OF THE HIGH-INTENSIVE FOCUSED ULTRASOUND IN TREATMENT HEPARHYDATIDECHINOCOCCOSIS.
}

\author{
S. Imankulov, A. Baygenzhin, K. Rustemova, G. Fedotovskikh, G. Shaimardanova, N. Zhampeissov and \\ M. Erlan. L. Knaub. \\ National Scientific Medical Research center, Astana, Kazakhstan.
}

\section{Manuscript Info}

Manuscript History

Received: 10 July 2016

Final Accepted: 19 August 2016

Published: September 2016

Key words:-

liver echinococcosis, the high-intensity

focused ultrasound, destruction of a

parasitic cyst, morphology.

\section{Abstract}

The morphological characteristics of the content and the wall 11 parasitic cysts hydatid echinococcus liver, with the impact of highintensity focused ultrasound. Complex histological, cytological examination revealed Electron and destruction of all elements of the germinal cysts and various parasite.

Copy Right, IJAR, 2016,. All rights reserved.

\section{Relevance:-}

Echinococcosis remains a heavy widespread chronic disease with the extensive, quite often system pathology leading to andisabilityand death of the person. In recent years in Kazakhstan the aggravation of an epidemiological situation with annual registration more than 1000 cases especially of inhabitants of the southern areas of the republic is observed [Musaev G.2006]. More often than other bodies this invasion in 50-70\% of supervision the liver is surprised. The current state of radical surgical treatment of echinococcosis of a liver is not satisfactory as has a number of contraindications, the high level of complications and considerable number of the recurrent forms leading to repeated operations.

Against introduction of alternative low-invasive technologies of treatment of echinococcosis of a liver our attention was drawn by the high-intensity focused ultrasound (HIFU-an ablyation) which is successfully applied in quality through skin impact on tumoral fabric [Nazarenko G.et al.2008;Ordabekov S.et al.2005]. Feature of this ultrasound is its temperature and cavitational effect.Effective use in our clinic of HIFU-of ablyation in treatments the ekhinokokkovykh of cysts of a liver [Li C.X.et al.2004; Wu F., et al.2004; Imankulov S.et al.2012]

\section{Objective:-}

Effective use in our clinic of HIFU-of ablyation in treatments the hydatid cysts of a liver [Imankulov S.et al.2015], demanded a complex morphological assessment of a condition of a capsule and contents of an ekhinokokkosis cyst at influences of this method, as was the purpose of the real research.

\section{The materials and methods of research:-}

Material for morphological study of biopsy material of the wall of the cyst and centrifuged content hydatid 11 brushes made by fine-needle percutaneous biopsy 3-4 days after HIFU ablation. Histological material was embedded in paraffin. Histological sections stained with hematoxylin and eosin, PAP smears-drugs - Romanovsky - Giemsa 
and Papanicolaou. For electron-microscopic examination of sedimentary material content hydatid brushes taken, fixed in $2 \%$ solution of glutaraldehyde with pasticceria in $1 \%$ solution of osmium tetroxide, was performed by the standard technique and is embedded in EPON. Semi-thin and ultrathin sections were obtained on a Leica ultramicrotome. Semi-thin sections were stained with methylene blue and Azur-2 and basic fuchsin (Humphrey C., Pittman F.A.1974). The sections were examined and photographed in an electron microscope Libra 120 (Carl Zeiss).

Ablyation of an hydatid cysts high-intensity focused by ultrasound was seen off on the equipment of the ZhTs model Fokused Ultrasound Therapeutis of Systems (Chungking of NIFU to the Technologist of the Companies, China) a medical lens with a diameter of 15 centimeters, with a frequency of radiation of $0,9 \mathrm{MHz}$ with the course of the focused ultrasound in vertical the directions, cuts of $5 \mathrm{~mm}$. The power of intensity of radiation average on time made $180-250 \mathrm{~W}$.

\section{Results of study and its discussion:-}

At histological study of hepatic tissue after affection of ultrasound the narrow band of the first zone attached to fibrous capsule of echinococcus, consisted of dystrophic and necrotic changes of hepatocytes. Situated further from fibrous capsule the hepatic tissue was unremarkable. Internal layers of fibrous capsule chitinous layer were fragmented and in the form of thick and thin bands separated together with attached structures of germinal layer (Fig.1). Electron-microscopic and laminar layers flaked and were characterized by disorder of distinct structuredness with sharp osmiophility and "angularity" of fiber material edges, appearance of electronic and transparent cavities in granular layer. Glycogen contained cells of the internal germinal layer with oxyphil colored poles of glycogen and lipid inclusions were desquamated and destroyed (Fig.2). In electron and microscopic manner the nuclei were pyknotic or were in the state of rrhexis, hyaloplasm with disruption foci (Fig.3). Large lipid drops, small ones about $300 \mathrm{~nm}$ osmiophilic granules with exfoliative electronic and transparent cover, multiple vesicles with homogenous or close-grained material, surrounded by single or composite membrane about $200 \mathrm{~nm}$ and more, filaments (Fig. 4) were related to the elements of destroyed cells of germinal layer - glycogen contained cells, miocytes, syncytes, tegument cyton, fragments of different germinal forms of parasit - complex cell composition of brood capsules and daughter larval cyst hydatid echinococcus.

At light-optical study in the overwhelming majority of cases the sedimentary material of echinococcus cyst content consisted of destroyed cells of germinal layer and neutrophils, fragments of laminar layers, elements of germinal structures freely lying vacuolar and granular material, small lime crystals (Fig. 5).In 3 of 9 cases there was existence of adult Protoscolex. On high magnification there was complete and partial destruction of parasites with vacuolization of tegument, fragmentation of everted heads with suckers and hooklets, destroying of cell membrane with vacuoles output (Fig.6). Protoscolex were in the state of induration with reducing of sizes and obvious thickening of cytoplasm (Fig.7). Separate Protoscolex were not disclosed, but lost syncytial surface layer with denudation of basal membrane and were characterized by sharp cells vacuolization of parasitic body (Fig.8). Basal membrane was thinned and sharply thickened, cells of deep layers of Protoscolex body were fragmented and free of clear ultrastructure (Fig.9).

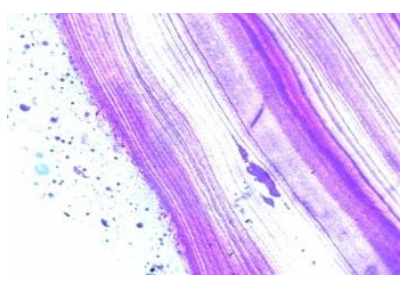

Fig.1:- Detachment of the chitinous layer. Separation of germinal layer elements. Semi-thin section. Coloring to methylen blue, azure - 2 and basic fuchsin.X1 000.

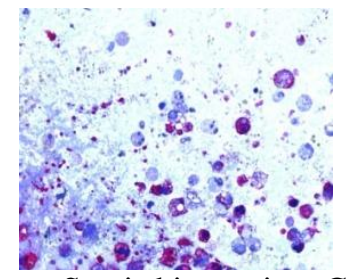

Fig.2:- Desquamated cells of the germinal layer. Semi-thin section. Coloring to methylen blue, azure - 2 and basic fuchsin.X1 000 . 


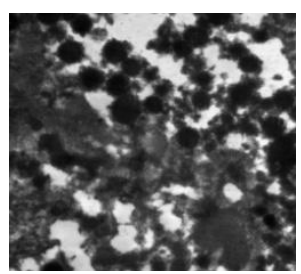

Fig.3:- Destruction of glycogen contained cell. Electron-diffraction photograph.

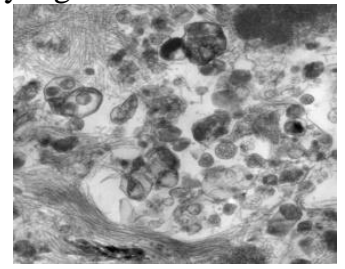

Fig.4:- Vesicular and fibriller structures of destroyed cells. Electron-diffraction photograph.

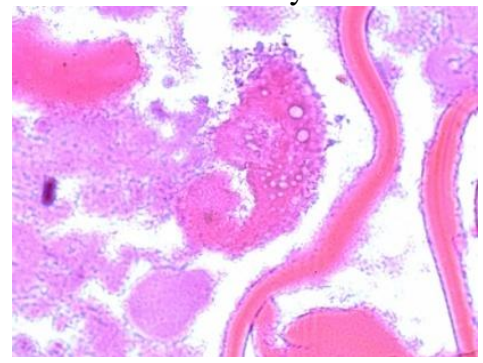

Fig.5:- Fragments of laminar layers and destruction of Protoscolex in the content of sedimentary material. Pap smear - preparation. Romanowsky-Giemsa stain.X 1000.

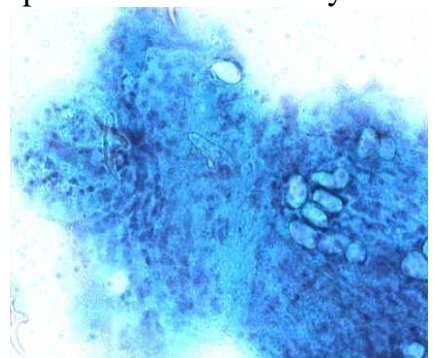

Fig.6:- Destruction of adult Protoscolex. Pap smear - preparation. Papanicolaou's stain.X 1000.

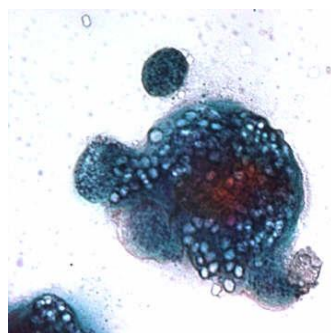

Fig.7:- Induration of adult Protoscolex. Pap smear - preparation. Papanicolaou's stain.X 1000.

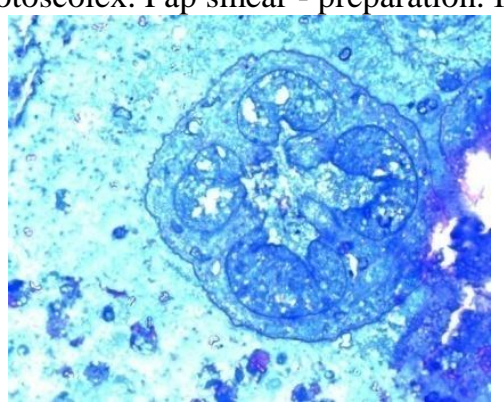


Fig.8:- Loss of syncytial layer and vacuolization of Protoscolex body. Semi - thin section. Coloring to methylen blue, azure - 2 and basic fuchsin.X1 000 .

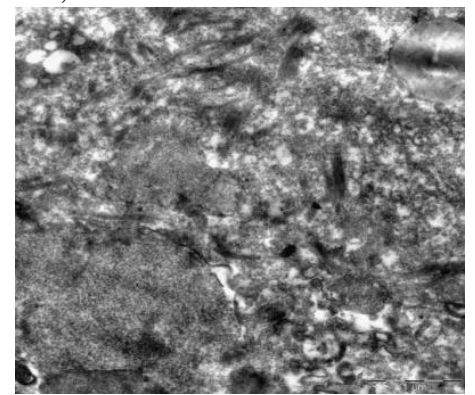

Fig.9:- Destruction of Protoscolex cells. Electron-diffraction photograph.

\section{Conclusion:-}

Thus, we have obtained the morphological evidence effects destructive high-intensity focused ultrasound a smature forms of hydatid tape wormand structure of the germinal membrane, which is a carrier of vital functions echinococcus.

\section{References:-}

1. Musayev G. (2005)Hydatid disease: state of the problem. J.Clinical prospects of gastroenterology, hepatology. Moscow.4;p.7-12.

2. Nazarenko G., Khitrova.KrasnovT.andBoldanov E.(2008) Innovative method of ultrasound ablation of human tumors (literature review and own observations) J.Ultrasonic and functional diagnostic - 4;p.53-74.

3. Ordabekov SO, Ordabekov ES and Temirova Z.(2005),Modern approach to the treatment of hepatic echinococcosis. Journal of Surgery Kazakhstan.-2;p.55-57.

4. Humphrey C., Pittman F.(1974) Simple methylene blue-azure 2 basic fuchsin stain for epoxy-embedded tissue sections. Stain Tehnol.-49;p.9-14.

5. Imankulov S., Fedotovskiy G., Shaymardanova G., Yerlan M., Zhampeisov N.(2012).Feasibility syudy of high intensity focused ultrasound (HIFU) for the treatment of hydatid cysts of the liver. J.Clinical Medicine of Kazakhstan.- 3;p.43-49

6. Li C.X., Xu G.L., Jang Z.Y. et al. (2004). Analysis of clinical effect of high-intensity focused ultrasound on liver cancer. World J.Gastroenterol.-10;p.2201-4.

7. Wu F., Wang Z., Chen W.et al.(2004). Advanced hepatocellular carcinoma: treatment with high-intensity focused ultrasound ablation combined with transcatheter arterialembolization. J. Radiology.-30; p.245-260

8. Imankulov S., Fedotovskikh G., Shaimardanova G.,Yerlan M.(2015).Feasibility study of high intensity focused ultrasound (HIFU) for the treatment of 2015hydatid cysts of the liver -Elsevier. J.Ultrasonicssonochemistry27;p.67-75. 